\title{
Synthesis and Recovery of Pyridine- and Piperidine-based Camphorsulfonamide Organocatalysts Used for Michael Addition Reaction
}

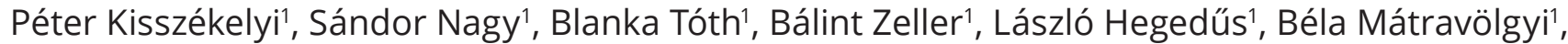 \\ Alajos Grün'1, Tamás Németh², Péter Huszthy¹, József Kupai*

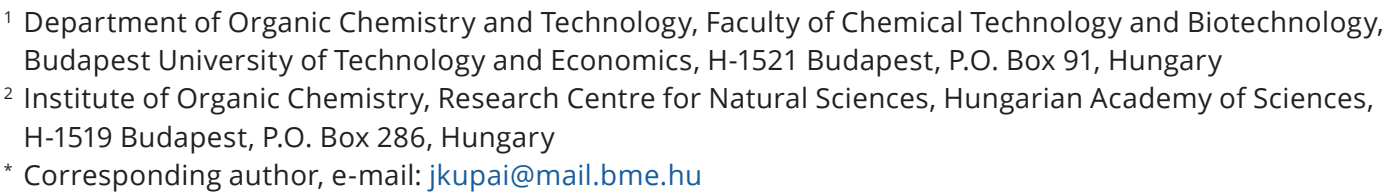

Received: 19 June 2018, Accepted: 11 September 2018, Published online: 31 October 2018

\begin{abstract}
Two new pyridine-based asymmetric bifunctional organocatalysts containing one or two camphorsulfonamide units were synthesized. Asymmetric Michael addition of pentane-2,4-dione to $\beta$-nitrostyrene was catalyzed by these organocatalysts. During our experiments, influence of the solvent and temperature on the yield and enantioselectivity was studied. Using monocamphorsulfonamide derivative the $S$ enantiomer of the corresponding Michael adduct was gained with moderate yield (up to $51 \%$ ) and low enantiomeric excess (up to $18 \%$ ). Organic solvent nanofiltration was successfully applied for the recovery of these organocatalysts. Furthermore, pyridine camphorsulfonamide was reduced to its piperidine derivative. Using piperidine monosulfonamide derivative racemic Michael adduct was obtained with excellent yield (up to $89 \%$ ). Beside its organocatalytic relevance, piperidine monosulfonamide derivative may also possess biological activity.
\end{abstract}

Keywords

organocatalyst, asymmetric synthesis, camphorsulfonamide, catalyst recovery, Michael addition

\section{Introduction}

Undoubtedly, using a catalytic amount of chiral controller is an elegant and economically attractive way to introduce chirality into a molecule. Among enantioselective reactions, methods based on metal-free chiral organocatalysts have become more significant [1-3]. We can state that asymmetric organocatalysis is one of the most rapidly growing research areas in synthetic organic chemistry $[4,5]$.

The application of camphor derivatives in asymmetric organic reactions is a well-known method for chirality transfer. Camphor is one of nature's privileged scaffolds, readily available in both stereoisomers, and it can be easily altered to provide a wide range of optically active compounds [6]. As important members of the camphor family, camphorsulfonamides were applied first as chiral auxiliaries [7-10], later as enantioselective organocatalysts [11-16]. One of these reactions is the organocatalytic asymmetric Michael reaction, which is a powerful synthetic method to generate new carbon-carbon bond with concomitant formation of a new stereogenic center [17-23]. Therefore, it can be applied in the synthesis of biologically important pharmaceuticals and chiral precursors for the synthesis of bioactive compounds (Fig. 1). [24-26]

Recently Huang et al. [15] prepared camphorsulfonamide type organocatalysts and they demonstrated that the camphorsulfonamide group can enhance the effectiveness of asymmetric Michael reaction. Beside their potential organocatalytic activity, piperidine-based camphorsulfonamides may have biological activity. [27, 28]

The potential for realizing synergies based on combining membrane separations with chemical processing in industry is expanding with the development of solvent-resistant nanofiltration membranes. Organic solvent nanofiltration (OSN) is an emerging technology that allows separation of solutes between 50 and $2000 \mathrm{~g} \cdot \mathrm{mol}^{-1}$ via pressure gradient [29]. OSN processes are considered to be sustainable, and there are recent attempts to improve the greenness of membrane 


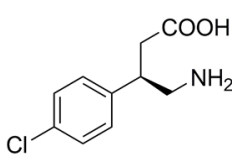

(R)-Baclofen antispastic agent

Fig. 1 Biologically active compounds synthesized by asymmetric Michael addition [27-31].

fabrication as well with the overall aim to improve the life cycle assessment (LCA) of the field [30, 31]. Consequently, OSN is an attractive approach for process intensification via soluble catalyst recovery [32, 33], pharmaceutical purification $[34,35]$, and iterative synthesis [36, 37].

Recently, we presented a preliminary study for the potential application of nanofiltration in the purification and recovery of crown ethers [38] and cinchona organocatalysts [39]. In continuation of these studies, our attention turned to the recycling of other types of catalysts. This article presents a preliminary study for exploring the potential of OSN in the recovery of camphorsulfonamide-based organocatalysts. Regarding these results, we are focusing on introducing some new, easily accessible bifunctional pyridine and piperidine-camphorsulfonamide-type organocatalysts, which can be recovered by OSN. To study the catalytic activity of enantiopure camphorsulfonamide derivatives, we apply them in asymmetric Michael addition reaction. Moreover, piperidine-based camphorsulfonamide is among the potential bioactive compounds with high pharmaceutical relevance.

\section{Experimental}

\subsection{Methods of characterization}

IR were recorded on a Bruker Alpha-T FT-IR spectrometer. Optical rotations were taken on a Perkin-Elmer 241 polarimeter (calibrated by measuring the optical rotations menthol). NMR spectra were recorded either on a Bruker DRX-500 Avance spectrometer or on a Bruker 300 Avance spectrometer. LC-MS was performed on an HPLC system using Gemini RP C18 column $(150 \times 4.6$ $\mathrm{mm}, 3 \mu \mathrm{m}, 256 \mathrm{~nm}, 40{ }^{\circ} \mathrm{C}, 0.6 \mathrm{~mL} / \mathrm{min}$, gradient elution: water $\left(0.1 \% \mathrm{NH}_{4} \mathrm{HCO}_{3}\right)$ - acetonitrile $\left(0.1 \% \mathrm{NH}_{4} \mathrm{HCO}_{3}\right.$ $+8 \%$ water)) in ESI mode. Elemental analyses were performed on a Vario EL III instrument (Elementanalyze Corp., Germany) in the Microanalytical Laboratory of the Department of Organic Chemistry, Institute for Chemistry, Eötvös Loránd University, Budapest, Hungary. Melting points were taken on a Boetius micro-melting point apparatus (uncorrected). The enantiomeric ratios of the samples were determined by chiral HPLC measurements using reversed phase mode (Thermo Finnigan Surveyor LC System, Phenomonex Lux Cellulose-3 column ( $3 \mu \mathrm{m}$, $250 \times 4.6 \mathrm{~mm}$ ), eluent $\mathrm{CH}_{3} \mathrm{CN} / 20 \mathrm{mM} \mathrm{NH}_{4} \mathrm{OAc}$ in $\mathrm{H}_{2} \mathrm{O}=$ 40/60, UV detector $222 \mathrm{~nm}, 0.6 \mathrm{~mL} \cdot \mathrm{min}^{-1}, 20^{\circ} \mathrm{C}$, retention time for $(R)-8$ : $11.9 \mathrm{~min}$, for $(S)-8: 14.2 \mathrm{~min})$.

Note: In our reactions we used a chlorinated solvent (DCM), but tert-butyl methyl ether, 2-methyltetrahydrofuran or dimethyl carbonate should be used instead. Experiments are in progress to change DCM to green solvents, and results will be published as soon as the work on it is finished.

\subsection{Materials}

Starting materials were purchased from Aldrich Chemical Company. Silica gel $60 \mathrm{~F}_{254}$ (Merck) plates were used for TLC. Silica gel 60 (70-230 mesh, Merck) were used for column chromatography. Ratios of solvents for the eluents are given in volumes $\left(\mathrm{mL} \cdot \mathrm{mL}^{-1}\right)$. Evaporations were carried out under reduced pressure.

\subsection{Preparation of (+)-1-[(1S)-7,7-Dimethyl-2- oxobicyclo[2.2.1]heptan-1-yl]-N-(6-methylpyridin-2-yl) methane sulfonamide $[(S)-1]$}

To a solution of 2-amino-6-methylpyridine (4, $100 \mathrm{mg}$, $0.925 \mathrm{mmol})$ and TEA $(145 \mu \mathrm{L}, 103 \mathrm{mg}, 1.017 \mathrm{mmol})$ in DCM $(10 \mathrm{~mL})$ was added a solution of $(1 S)-(+)$-10-camphorsulfonyl chloride (255 mg, $1.017 \mathrm{mmol})$ in DCM $(10 \mathrm{~mL})$ at $0{ }^{\circ} \mathrm{C}$ and the resulting mixture was stirred at room temperature overnight. After the reaction was completed, the solution was poured into water $(30 \mathrm{~mL})$, and was extracted with DCM $(3 \times 30 \mathrm{~mL})$. The combined organic phase was dried over

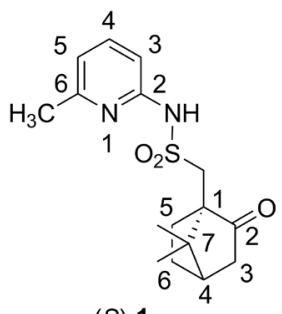

(S)-1

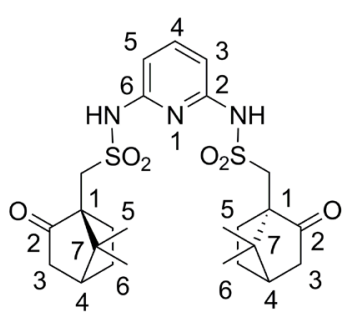

$(S, S)-2$

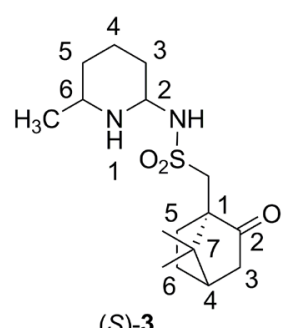

(S)-3

Fig. 2 Synthesized new camphorsulfonamide derivatives 
anhydrous $\mathrm{MgSO}_{4}$, filtered and the solvent was evaporated. The crude product was purified by column chromatography on silica gel (1:6 MeOH-toluene) to give camphorsulfonamide $(S)-\mathbf{1}(288 \mathrm{mg}, 87 \%)$ as an off-white solid.

$M p: 101-102{ }^{\circ} \mathrm{C}(\mathrm{MeOH}) ; R_{F}: 0.39$ (silica TLC, $\mathrm{MeOH}-$ toluene 1:6); $\alpha^{\mathrm{D}}{ }_{25}=+9.2$ (c 1.00, DCM); IR (KBr) $v_{\text {max }} 3102$ $\left(v_{a s}, \mathrm{NH}\right), 2956\left(v_{a s}, \mathrm{CH}\right), 2889\left(v_{s}, \mathrm{CH}\right), 1740(v, \mathrm{C}=\mathrm{O})$, 1617 ( $v,=\mathrm{CH}, \mathrm{Py}), 1579(v,=\mathrm{CH}, \mathrm{Py}), 1454\left(\delta_{a s}, \mathrm{CH}_{3}\right), 1414$ $\left(\delta_{a s}, \mathrm{CH}_{3}\right.$; and $\left.\beta_{s}, \mathrm{CH}_{3}\right), 1391\left(\delta_{s}, \mathrm{CH}_{3}\right), 1351\left(v_{a s}, \mathrm{SO}_{2}\right), 1272$ $(\gamma, \mathrm{C}-\mathrm{N}), 1124\left(v_{s}, \mathrm{SO}_{2}\right), 791(\gamma,=\mathrm{CH}, \mathrm{Py}), 763(\gamma,=\mathrm{CH}$, Py) $\mathrm{cm}^{-1} ;{ }^{1} \mathrm{H}$ NMR $\left(300 \mathrm{MHz}, \mathrm{CDCl}_{3}\right) \delta(\mathrm{ppm}) 0.86(s, 3 \mathrm{H}$, $\left.\mathrm{CH}_{3}\right), 1.09\left(s, 3 \mathrm{H}, \mathrm{CH}_{3}\right), 1.44-1.50$ ( $m, 1 \mathrm{H}$, camphor H-6), 1.93-1.99 ( $m, 2 \mathrm{H}, \mathrm{H}-5$ and 5'), 2.06-2.12 ( $m, 2 \mathrm{H}, \mathrm{H}-6{ }^{\prime}$ and $\mathrm{H}-4), 2.29-2.37$ ( $m, 2 \mathrm{H}$, camphor H-3 and 3'), 2.50 ( $s, 3 \mathrm{H}$, Py- $\left.\mathrm{CH}_{3}\right), 3.15\left(d, J=15 \mathrm{~Hz}, 1 \mathrm{H}, \mathrm{CH}_{2}\right), 3.59(d, J=15 \mathrm{~Hz}$, $\left.1 \mathrm{H}, \mathrm{CH}_{2}\right), 6.65(d, J=7.5 \mathrm{~Hz}, 1 \mathrm{H}$, pyridyl-H-3), 7.00 $(d, J=7.5 \mathrm{~Hz}, 1 \mathrm{H}$, pyridyl-H-5), $7.56(t, J=7 \mathrm{~Hz}, 1 \mathrm{H}$, pyridyl-H-4), 10.17 (br. s, 1H, NH); ${ }^{13} \mathrm{C}$ NMR (75.5 MHz, $\left.\mathrm{CDCl}_{3}\right) \delta$ (ppm) 19.8 (camphor $\mathrm{CH}_{3}$ ), 19.9 (camphor $\mathrm{CH}_{3}$ ), 21.8 (Py- $\mathrm{CH}_{3}$ ), 25.2 (camphor), 27.0 (camphor), 42.7 (camphor), 42.8 (camphor), 48.4 (camphor), 50.2 (camphor), 58.7, 114.3 (pyridyl), 114.6 (pyridyl), 140.6 (pyridyl), 151.2 (pyridyl), 153.3 (pyridyl), $215.9(\mathrm{C}=\mathrm{O})$; Anal. calcd for $\mathrm{C}_{16} \mathrm{H}_{22} \mathrm{~N}_{2} \mathrm{O}_{3} \mathrm{~S}$ : C, 59.60; H, 6.88; N, 8.69; S, 9.95. Found: C, 59.42; H, 6.97; N, 8.68; S, 9.99.

\subsection{Preparation of $(+)-(S)-N, N^{\prime}-($ Pyridine-2,6-diyl) bis(1-((1S)-7,7-dimethyl-2-oxobicyclo[2.2.1]heptan-1- yl)methanesulfonamide) $[(S, S)-2]$}

To a solution of 2,6-diaminopyridine $(\mathbf{5}, 100 \mathrm{mg}, 0.916 \mathrm{mmol})$ and TEA $(280 \mu \mathrm{L}, 204 \mathrm{mg}, 2.016 \mathrm{mmol})$ in DCM $(10 \mathrm{~mL})$ was added a solution of $(1 S)-(+)-10$-camphorsulfonyl chloride $(505 \mathrm{mg}, 2.016 \mathrm{mmol})$ in DCM $(10 \mathrm{~mL})$ at $0{ }^{\circ} \mathrm{C}$ and the resulting mixture was stirred at room temperature overnight. After the reaction was completed, the solution was poured into water $(30 \mathrm{~mL})$, and was extracted with DCM $(3 \times 30 \mathrm{~mL})$. The combined organic phase was dried over anhydrous $\mathrm{MgSO}_{4}$, filtered and the solvent was evaporated. The crude product was purified by column chromatography on silica gel (1:5 IPA-toluene) to give biscamphorsulfonamide $(S, S)-\mathbf{2}(408.8 \mathrm{mg}, 83 \%)$ as a pale yellow oil.

$R_{F}: 0.42$ (silica TLC, MeOH-toluene 1:6); $\alpha_{25}^{D}=+1.4$ (c 1.00, DCM); IR (film) $v_{\max } 3250\left(v_{a s}, \mathrm{NH}\right), 2961$ (v, CH), 1735 ( $v, \mathrm{C}=\mathrm{O}), 1598$ ( $v,=\mathrm{CH}, \mathrm{Py}), 1586$ ( $v,=\mathrm{CH}, \mathrm{Py}), 1459$ $(v,=\mathrm{CH}, \mathrm{Py}), 1415\left(\delta_{a s}, \mathrm{CH}_{3}\right.$; and $\left.\beta_{s}, \mathrm{CH}_{3}\right), 1332\left(v_{a s}, \mathrm{SO}_{2}\right)$, $1137\left(v_{s}, \mathrm{SO}_{2}\right), 911(\gamma, \mathrm{S}-\mathrm{N}), 790(\gamma,=\mathrm{CH}, \mathrm{Py}), 728\left(\beta_{s}, \mathrm{CH}_{2}\right)$ $\mathrm{cm}^{-1} ;{ }^{1} \mathrm{H}$ NMR $\left(500 \mathrm{MHz}, \mathrm{CDCl}_{3}\right) \delta(\mathrm{ppm}) 0.91(s, 6 \mathrm{H}$, $\left.2 \times \mathrm{CH}_{3}\right), 1.07\left(s, 6 \mathrm{H}, 2 \times \mathrm{CH}_{3}\right), 1.44-1.50(m, 2 \mathrm{H}, 2 \times$ camphor H-6), 1.93-1.99 ( $m, 4 \mathrm{H}, 2 \times$ camphor H-5, H-5'), 2.02-2.09 ( $m, 2 \mathrm{H}, 2 \times$ camphor H-6'), 2.11-2.13 ( $m, 2 \mathrm{H}$, $2 \times$ camphor H-4), 2.29-2.33 ( $m, 2 \mathrm{H}, 2 \times$ camphor $\mathrm{H}-3)$, 2.38-2.43 ( $m, 2 \mathrm{H}, 2 \times$ campyhor H-3'), $3.37(d, J=15 \mathrm{~Hz}$, $\left.2 \mathrm{H}, \mathrm{CH}_{2}\right), 3.94\left(d, J=15 \mathrm{~Hz}, 2 \mathrm{H}, \mathrm{CH}_{2}\right), 6.91(d, J=7.5 \mathrm{~Hz}$, $2 \mathrm{H}$, pyridyl-H-3 and $\mathrm{H}-5), 7.66(t, J=8 \mathrm{~Hz}, 1 \mathrm{H}$, pyridyl-H-4), 8.26 (br. s, 2H, NH); ${ }^{13} \mathrm{C}$ NMR (125 MHz, $\left.\mathrm{CDCl}_{3}\right) \delta(\mathrm{ppm}) 19.7\left(\mathrm{CH}_{3}\right), 19.9\left(\mathrm{CH}_{3}\right), 26.4$ (camphor), 27.2 (camphor), 43.0 (camphor), 48.9 (camphor), 51.0 (camphor), 59.2, 107.1 (pyridyl), 141.1 (pyridyl), 150.5 (pyridyl), 215.8 $(\mathrm{C}=\mathrm{O})$; Anal. calcd for $\mathrm{C}_{25} \mathrm{H}_{35} \mathrm{~N}_{3} \mathrm{O}_{6} \mathrm{~S}_{2}$ : C, 55.84; H, 6.56; N, 7.81; S, 11.93. Found: C, 55.78; H, 6.62; N, 7.80; S, 11.95.

\subsection{Preparation of (S)-(-)-3-(2-Nitro-1-phenylethyl) pentane-2,4-dione $[(S)-8]$}

Organocatalyst $(S)$-1 or $(S)$-3 (0.3 eq) and $\beta$-nitrostyrene $(7,1.0 \mathrm{eq})$ were added to a solution of pentane-2,4-dione $(6,2.5 \mathrm{eq})$ in different solvents (Table 1-2). The reaction mixture was stirred at room temperature or at $50{ }^{\circ} \mathrm{C}$. After $48 \mathrm{~h}$, the solvent was removed. The crude product was purified by preparative thin layer chromatography on silica gel (2:1 hexane-ethyl acetate) to give Michael adduct $\mathbf{8}$ as a white solid (yields and e.e. values can be seen in Table 1-2).

Table 1 Michael Addition of acetylacetone (6) to nitrostyrene (7) catalyzed by $(S)-\mathbf{1}^{12}$

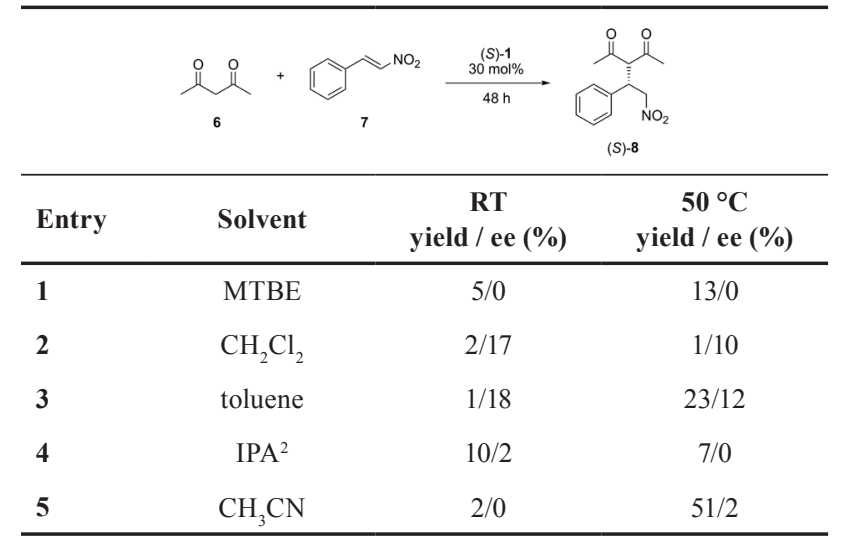

M.p.: $123-126^{\circ} \mathrm{C}$ (lit. mp: $\left.124-126^{\circ} \mathrm{C},[40]\right) ; \alpha^{D}{ }_{25}=+1.3$ (c $0.32, \mathrm{CHCl}_{3}, 17 \%$ ee); lit. $\alpha_{25}^{D}=+196.7$ (c 1.01, $\mathrm{CHCl}_{3}$, $88 \%$ ee, [40]); $R_{F}: 0.39$ (silica TLC, acetone-chloroform 1:100). The obtained product had the same spectroscopic data than those of reported [40].

1 Reaction conditions: pentane-2,4-dione (2.5 eq), nitrostyrene (1 eq), organocatalyst $(0.3 \mathrm{eq})$, solvent $(0.5 \mathrm{~mL}), 48 \mathrm{~h}$ and at room temperature or $50{ }^{\circ} \mathrm{C}$. Conversion and enantiomeric excess were determined by LCMS and chiral HPLC, respectively.

2 IPA: 2-propanol 


\subsection{Preparation of (+)-1-[(1S)-7,7-Dimethyl-2-} oxobicyclo[2.2.1]heptan-1-yl]- $N$-(6-methylpiperidin-2yl) methane sulfonamide [(S)-3]

The hydrogenation reaction was carried out in an $80 \mathrm{~mL}$ stainless steel autoclave (Technoclave, Budapest, Hungary) equipped with a magnetic stirrer (stirring speed: $1100 \mathrm{rpm})$. The reactor containing sulfonamide $(S)-1$ (300 mg, $0.930 \mathrm{mmol}), 10 \% \mathrm{Pd} / \mathrm{C}$ (Selcat Q) catalyst $(120 \mathrm{mg})$ and $\mathrm{MeOH}(20 \mathrm{~mL})$ was flushed with nitrogen and hydrogen, then charged with hydrogen (12 bar) and heated to $80{ }^{\circ} \mathrm{C}$. After the reaction was completed $(8 \mathrm{~h})$, the catalyst was filtered off and the solvent was removed to yield $(S)-3(242 \mathrm{mg}, 78 \%)$ as a colourless oil. The product was used without further purification.

$R_{F}: 0.78$ (silica TLC, DCM-MeOH 1:20); $\alpha_{25}^{D}=+31.2$ (c 1.00, DCM); IR (KBr) $v_{\max } 3277\left(v_{a s}, \mathrm{NH}\right), 3158,2960$ $\left(v_{a s}, \mathrm{CH}\right), 2928,2887\left(v_{s}, \mathrm{CH}\right), 1738(v, \mathrm{C}=\mathrm{O}), 1596(\beta, \mathrm{NH})$, $1457\left(\delta_{a s}, \mathrm{CH}_{3}\right.$; and $\left.\beta_{s}, \mathrm{CH} 2\right), 1327\left(v_{a s}, \mathrm{SO}_{2}\right), 1123\left(v_{s}, \mathrm{SO}_{2}\right)$, $813(\gamma, \mathrm{N}-\mathrm{H}) \mathrm{cm}^{-1} ;{ }^{1} \mathrm{H}$ NMR $\left(500 \mathrm{MHz}, \mathrm{CDCl}_{3}\right) \delta(\mathrm{ppm})$ $0.85\left(s, 3 \mathrm{H}\right.$, camphor $\left.\mathrm{CH}_{3}\right), 1.07\left(s, 3 \mathrm{H}\right.$, camphor $\left.\mathrm{CH}_{3}\right)$, $1.31\left(d d, J=6.5,3.8 \mathrm{~Hz}, 3 \mathrm{H}\right.$, piperidine $\left.\mathrm{CH}_{3}\right), 1.36-1.48$ (m, 2H), 1.64-1.77 (m, 1H), 1.80-1.99 (m, 4H), 1.99-2.07 ( $m, 1 \mathrm{H}), 2.09(t, J=4.5 \mathrm{~Hz}, 1 \mathrm{H}), 2.31-2.58(m, 5 \mathrm{H}), 2.95$ $(d d, J=14.5,3 \mathrm{~Hz}, 1 \mathrm{H}), 3.47\left(d, J=15 \mathrm{~Hz}, 1 \mathrm{H}, \mathrm{CH}_{2}\right), 3.48$ $\left(d, J=15 \mathrm{~Hz}, 1 \mathrm{H}, \mathrm{CH}_{2}\right), 3.54-3.64(m, 1 \mathrm{H}), 8.37(d, J=11.5$ $\mathrm{Hz}, 1 \mathrm{H}, \mathrm{NH}) ;{ }^{13} \mathrm{C}$ NMR $\left(125 \mathrm{MHz}, \mathrm{CDCl}_{3}\right) \delta$ (ppm) 18.5, 18.6, 19.8 and 19.8, 22.3, 24.3 and 24.4, 27.0, 29.5 and 29.6, 30.7 and $30.7,42.6$ and $42.6,42.7$ and 42.7, 48.2 and 48.2 , 49.2, 49.6 and 49.6, 50.7, 58.2 and 58.2, 215.8 and 216.0; Anal. calcd for $\mathrm{C}_{16} \mathrm{H}_{28} \mathrm{~N}_{2} \mathrm{O}_{3} \mathrm{~S}: \mathrm{C}, 58.50 ; \mathrm{H}, 8.59 ; \mathrm{N}, 8.53 ; \mathrm{S}$, 9.76. Found: C, 58.48; H, 8.62; N, 8.50; S, 9.79.

\section{Results and discussion}

\subsection{Synthesis and application of new, enantiopure pyridine-camphorsulfonamide derivatives}

Our aim was to prepare new camphorsulfonamide derivatives as potential bifunctional organocatalysts. The simultaneous activation of the electrophile by the hydrogen bond donor sulfonamide unit and the nucleophile by the Brønsted basic group (pyridine nitrogen) together with the chiral camphor-skeleton, should provide enough interaction between the reactants and the organocatalyst to accomplish enantioselective reactions.

As starting materials for this synthetic strategy, the relatively cheap and commercially available 2 -amino-6-methylpyridine (4) and 2,6-diaminopyridine (5) were chosen. These amines were transformed to their mono- $[(S)-1]$ and bissulfonamide $[(S, S)$-2] derivatives (Fig. 3), respectively, by
Table 2 Michael Addition of acetylacetone to nitrostyrene catalyzed by $(S)-\mathbf{3}^{\mathrm{a}}$

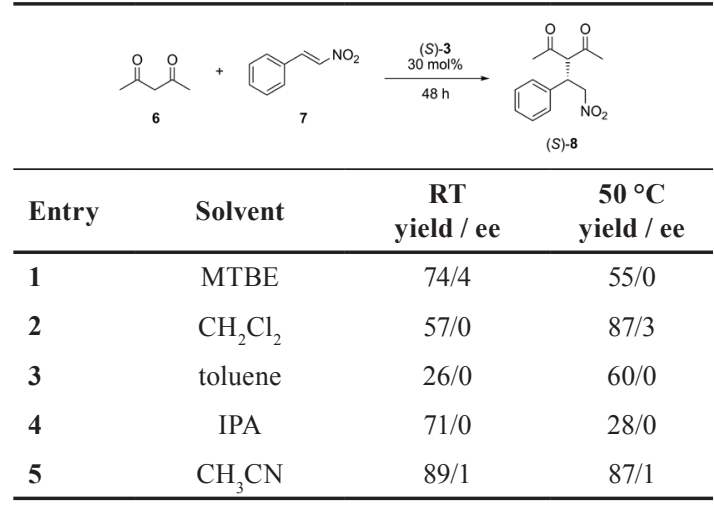<smiles>[X]c1cccc(NS(=O)(=O)Nc2cccc(CC(C)C)n2)n1</smiles>

$$
4\left(\mathrm{X}=\mathrm{CH}_{3}\right)
$$$$
\text { (S)-1 }\left(\mathrm{X}=\mathrm{CH}_{3}\right)(87 \%)
$$

$(S, S)-2\left(X=\mathrm{NH}_{2} \mathrm{SO}_{2} \mathrm{Cam}\right)(83 \%)$

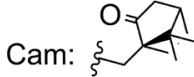

Fig. 3 Synthesis of camphorsulfonamide derivatives $(S)-\mathbf{1}$ and $(S, S)-\mathbf{2}$

treating with one or two equivalents of $(S)$-camphorsulfonyl chloride in the presence of triethylamine (TEA).

New organocatalysts $(S)$-1 and $(S, S)$-2 were used in the Michael addition of pentane-2,4-dione (6) to $\beta$-nitrostyrene (7) (Table 1). The reactions were carried out in five different solvents using $30 \mathrm{~mol} \%$ catalyst. Compound $(S, S)-\mathbf{2}$ showed no catalytic activity. Using $(S)-\mathbf{1}$ as a catalyst at room temperature, both the yield and the enantiomeric excess were low. Increasing the temperature to $50{ }^{\circ} \mathrm{C}$ resulted in a small (MTBE, toluene) or significant $\left(\mathrm{CH}_{3} \mathrm{CN}\right)$ improvement in the yield, while the enantioselectivity of the reaction remained low.

\subsection{Catalyst recovery via nanofiltration}

Preliminary studies were carried out to evaluate the feasibility of OSN for recovery of camphorsulfonamides $(S)$-1 and $(S, S)$-2. Membranes were fabricated based on recently established method [41, 42]. Polybenzimidazole membranes (18 wt $\%$ and $22 \mathrm{wt} \%$ denoted as $18 \mathrm{PBI}$ and $22 \mathrm{PBI})$ crosslinked with $\alpha, \alpha^{\prime}$-dibromo- $p$-xylene were used for the filtration studies. Solutes were dissolved in 


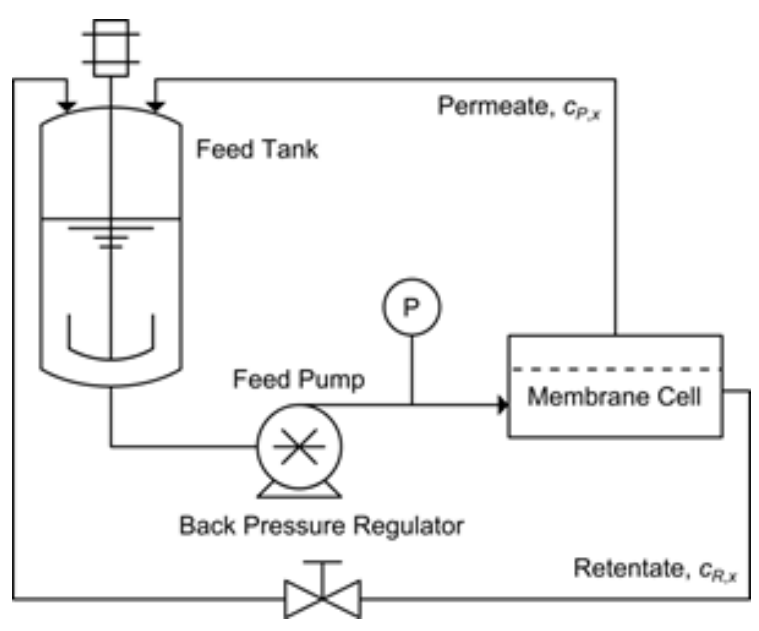

Fig. 4 Schematic diagram of the utilized nanofiltration process

toluene $\left(0.1 \mathrm{~g} \cdot \mathrm{L}^{-1}\right)$ and loaded into the nanofiltration rig. The nanofiltration was carried out in cross-flow configuration with $100 \mathrm{~L} \cdot \mathrm{h}^{-1}$ recirculation at 30 bar (Fig. 4).

Permeate flux was measured and permeate and retentate samples were taken at steady state after approximately $4 \mathrm{~h}$ of continuous operation. Solvent fluxes $(F)$ and solute rejections $(R)$ were calculated as given in Eq. $(1)^{3}$ and Eq. $(2)^{4}$, respectively:

$$
\begin{aligned}
& F=V_{P} \cdot A_{m}^{-1} \cdot t^{-1} \\
& R_{x}=1-c_{P, x} \cdot c_{R, x}^{-1} .
\end{aligned}
$$

The experimental rejections obtained for $(S)-\mathbf{1}$ and $(S, S)-2$ in THF, IPA and toluene ${ }^{5}$ at 30 bar using 18 PBI and 22 PBI are demonstrated in Fig. 5(A). The corresponding solvent fluxes are shown in Fig. 5(B).

As expected, the tighter membranes (22 PBI) have higher camphorsulfonamide rejection but lower flux values. Due to the larger molecular weight, $(S, S)-\mathbf{2}$ has higher rejection compared to $(S)-\mathbf{1}$ in all the tested solvents and membranes. The obtained rejection values also reveal that the rejection difference between the sulfonamides is smaller for the tighter membranes irrespectively of the solvent. The catalyst rejections vary between $48 \%$ and $99 \%$. Efficient recovery necessitates rejections of virtually $100 \%$. Consequently, both IPA and THF can be used for nanofiltration with 22 PBI featuring a modest

$3 F$ : permeate flux, $V_{P}$ : volume of permeate, $A_{m}:$ membrane area, $t$ : time $4 R_{x}$ : rejection of compound $x, c_{P, x}$ : permeate concentration of compound $x, c_{R, x}:$ retentate concentration of compound $x$.

5 Solvent selection was based on their different chemical characteristic (ether, alcohol and aromatic compound), also, industrial utilization as solvent was considered.
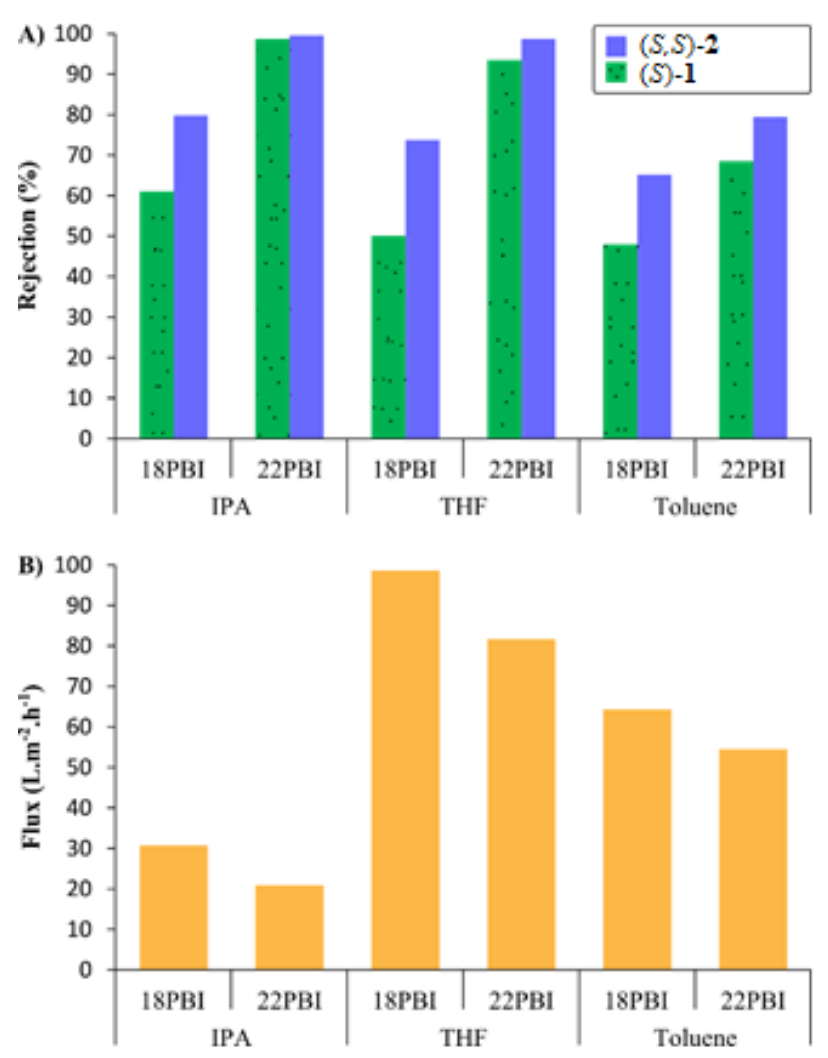

Fig. 5 Rejection of camphorsulfonamides on polybenzimidazole membranes at 30 bar (A) and the corresponding solvent flux values (B)

$20 \mathrm{~L} \cdot \mathrm{m}^{-2} \cdot \mathrm{h}^{-1}$ and an excellent $82 \mathrm{~L} \cdot \mathrm{m}^{-2} \cdot \mathrm{h}^{-1}$ fluxes, respectively.

Nanofiltration processes are usually operated in diafiltration mode. Based on the experimentally obtained rejection values, Fig. 6 shows the simulated concentration profile of the compounds during single-stage diafiltration.

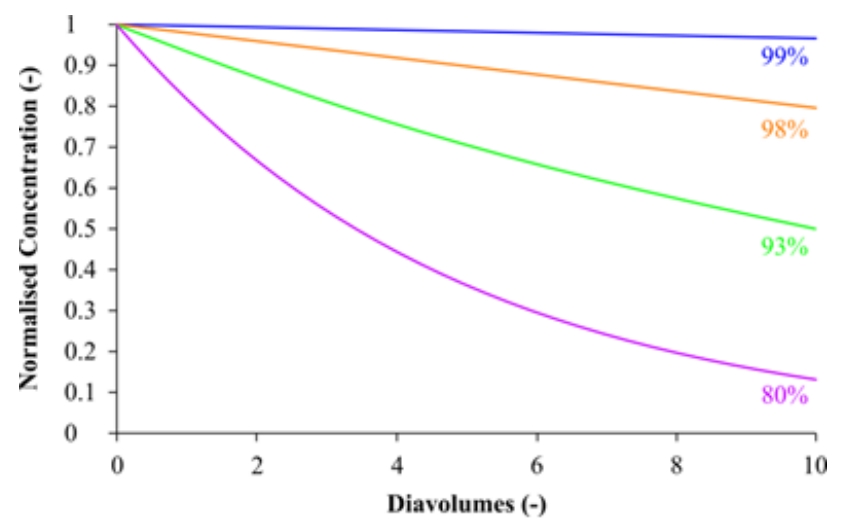

Fig. 6 Simulated camphorsulfonamide concentration profiles. ${ }^{6}$

6 The solute rejection values are given as percentages on the plot, from top to bottom: $(S, S)-\mathbf{2}$ on 22 PBI in THF, $(S)-\mathbf{1}$ on 22 PBI in IPA, $(S)-\mathbf{1}$ on $22 \mathrm{PBI}$ in THF and $(S, S)-2$ on $18 \mathrm{PBI}$ in IPA. 
These results confirm that OSN can be practically used for the recovery, only when rejections are $>98 \%$. Insufficient rejection leads to significant catalyst loss during single-stage nanofiltration process. For instance, $93 \%$ rejection results in $50 \%$ catalyst loss in 10 diavolume processing time. However, recent process advancement of the OSN field suggests that employing a threestage cascade configuration can address the inherent limitation of diafiltration processes: low yield and high solvent consumption [43-46]. Moreover, solvent treatment of the PBI membranes could also enhance the process performance [47]. OSN can be synergistically combined with adsorption processes to achieve better performance, i.e. improved yield or purity [48]. Based on our preliminary nanofiltration results, we plan to enhance the organocatalyst recovery via cascade approach and hybrid processes.

\subsection{Synthesis and application of new, enantiopure piperidine-camphorsulfonamide derivative}

Considering the low reaction yields of the Michael reaction (Table 1) catalyzed by $(S)-\mathbf{1}$, and the fact, that $(S, S)-\mathbf{2}$ has not been eligible for the addition reaction, we assumed that $K_{b}$ of the basic pyridine nitrogen is not high enough. Thus, it is conceivable that if we increase the basicity of the corresponding nitrogen, then higher conversion could be achieved. Accordingly, we synthesized analogue piperidine derivative $(S)$-3 by catalytic hydrogenation of $(S)$-1 (Fig. 7) using our published method [38].

The newly prepared piperidine derivative $(S) \mathbf{- 3}$ was also applied in Michael addition reaction (Table 2). As a confirmation of our assumption, the reaction yields at room temperature were significantly higher than in case of catalyst $(S)$-1.

Increasing the temperature to $50{ }^{\circ} \mathrm{C}$ resulted in higher yields in toluene and DCM, while using MTBE or IPA provided a decrease in the amount of products due to appearance of side-products. The products isolated at both temperatures were practically racemic. The best yield (89\%) was achieved in acetonitrile at room temperature.

Since the size of compounds $(S)-\mathbf{1}$ and $(S)-\mathbf{3}$ are almost equivalent, presumably their rejection is also identical.

\section{References}

[1] Dalko, P. I. "Comprehensive Enantioselective Organocatalysis: Catalysts, Reactions, and Applications", 1st ed., John Wiley \& Sons, Inc., Weinheim, Germany, 2013. https://oi.org/10.1002/9783527658862<smiles>CCCCCCCS(=O)(=O)Nc1cccc(C)n1</smiles>

(S)-1
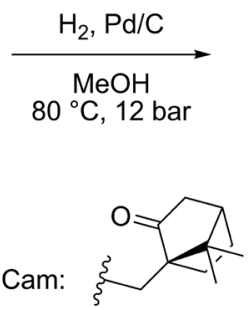

$80^{\circ} \mathrm{C}, 12$ bar
(S)-3 (78\%)

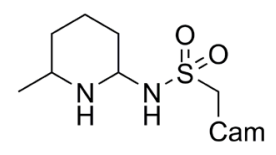

Fig. 7 Synthesis of camphorsulfonamide derivative $(S)-\mathbf{3}$

In consideration of the results of the catalyzed Michael reactions at room temperature, among the examined membrane separation combinations, IPA can be the appropriate solvent for recycling both organocatalysts.

\section{Conclusion}

The applications of three easily synthesized camphorsulfonamide organocatalysts $[(S)-\mathbf{1},(S, S)-\mathbf{2}$ and $(S)-\mathbf{3}]$ in Michael addition reaction have been presented. However, using pyridine-monocamphorsulfonamide $(S)$-1 only moderate yield and low enantioselectivity were achieved. The piperidine-based $(S)$-3, thanks to its higher basicity, gave racemic Michael adduct with higher yield (up to $89 \%$ ). The effect of solvent and temperature was considered, using acetonitrile at room temperature resulted in the most effective transformation without appearance of side-products.

The feasibility of OSN for recovery of organocatalysts [(S)-1 and $(S, S)$-2] was also demonstrated. Both IPA and THF can be used for nanofiltration with 22 PBI membrane featuring modest and excellent fluxes, respectively. The hybrid process including the application and recovery of the new organocatalysts will be reported as soon as that work is finished.

\section{Acknowledgement}

Financial support of the National Research - Development and Innovation Office (NKFIH/OTKA No. K 112289), the János Bolyai Research Scholarship of the Hungarian Academy of Sciences, the Servier-Beregi PhD Research Fellowship and the Gedeon Richter's Talentum Foundation is gratefully acknowledged.
[2] Mátravölgyi, B., Kovács, E., Hegedús, L., Jászay, Z., Thurner, A., Deák, S., Erdélyi, Z., Pham, T. S., Gönczi, K., Sólyom, S., Tőke, L., Faigl, F. "Synthesis and Application of New, Optically Active Compounds as Catalysts and Ligands in Enantioselective Reactions", Periodica Polytechnica Chemical Engineering, 59(1), pp. 38-50, 2015.

https://doi.org/10.3311/PPch.7320 
[3] Bakó, P., Rapi, Z., Keglevich, G. "Sugar-based Crown Ethers in Enantioselective Syntheses", Periodica Polytechnica Chemical Engineering, 59(1), pp. 51-58, 2015.

https://doi.org/10.3311/PPch.7308

[4] Volla, C. M. R., Atodiresei, I., Rueping, M. "Catalytic C-C BondForming Multi-Component Cascade or Domino Reactions: Pushing the Boundaries of Complexity in Asymmetric Organocatalysis", Chemical Reviews, 114(4), pp. 2390-2431, 2014.

https://doi.org/10.1021/cr400215u

[5] Govender, T., Arvidsson, P. I., Maguire, G. E. M., Kruger, H. G., Naicker, T. "Enantioselective Organocatalyzed Transformations of $\beta$-Ketoesters", Chemical Reviews, 116(16), pp. 9375-9437, 2016. https://doi.org/10.1021/acs.chemrev.6b00156

[6] Grošelj, U. "Camphor-Derivatives in Asymmetric Organocatalysis - Synthesis and Application", Current Organic Chemistry, 19(21), pp. 2048-2074, 2015. https://doi.org/10.2174/1385272819666150713180204

[7] Hsu, C.-Y., Lin, Y.-S., Uang, B.-J. " Enantioselective synthesis of (2S)-1-benzyloxy-2,3-propanediol and (2R)-1-amino-2,3propanediol from glycerol", Tetrahedron: Asymmetry, 1(4), pp. 219-220, 1990 .

https://doi.org/10.1016/S0957-4166(00)86327-2

[8] Ramón, D. J., Yus, M. "First enantioselective addition of diethylzinc and dimethylzinc to prostereogenic ketones catalysed by camphorsulfonamide-titanium alkoxide derivatives", Tetrahedron, 54(21), pp. 5651-5666, 1998.

https://doi.org/10.1016/S0040-4020(98)00236-1

[9] Chen, F.-Y., Uang, B.-J. "Enantioselective Synthesis of (R)-3-(3,4Dihydroxyphenyl)alanine from tert-Butyl Glycinate", The Journal of Organic Chemistry, 66(10), pp. 3650-3652, 2001. https://doi.org/10.1021/jo015569c

[10] Lu, G., Li, X., Jia, X., Chan, W. L., Chan, A. S. C. "Enantioselective Alkynylation of Aromatic Ketones Catalyzed by Chiral Camphorsulfonamide Ligands", Angewandte Chemie International Edition, 42(41), pp. 5057-5058, 2003.

https://doi.org/10.1002/anie.200352013

[11] Lemay, M., Ogilvie, W. W. "Aqueous Enantioselective Organocatalytic Diels-Alder Reactions Employing Hydrazide Catalysts. A New Scaffold for Organic Acceleration", Organic Letters, 7(19), pp. 4141-4144, 2005. https://doi.org/10.1021/o1051476w

[12] Martínez, R., Zoli, L., Cozzi, P. G., Ramón, D. J., Yus, M. "Synthesis of camphorsulfonamide-based quinoline ligands and their N-oxides: first use in the enantioselective addition of organozinc reagents to aldehydes", Tetrahedron: Asymmetry, 19(22), pp. 2600-2607, 2008.

https://doi.org/10.1016/j.tetasy.2008.10.020

[13] Kozakiewicz, A., Ullrich, M., Wełniak, M., Wojtczak, A. "Synthesis, structure and activity of sulfonamides derived from $(+)$-camphor in the enantioselective addition of diethylzinc to benzaldehyde", Journal of Molecular Catalysis A: Chemical, 326(1-2), pp. 128-140, 2010.

https://doi.org/10.1016/j.molcata.2010.04.019

[14] Grošelj, U., Golobič, A., Stare, K., Svete, J., Stanovnik, B. "Synthesis and structural elucidation of novel camphor-derived thioureas", Chirality, 24(4), pp. 307-317, 2012.

https://doi.org/10.1002/chir.21999
[15] Huang, Y.-C., Uang, B.-J. "Remote Sulfonamido Group Enhances Reactivity and Selectivity for Asymmetric Michael Addition of Nitroalkanes to $\alpha, \beta$-Unsaturated Aldehydes", Chemistry an Asian Journal, 9(9), pp. 2444-2448, 2014.

https://doi.org/10.1002/asia.201402516

[16] Wu, H.-L., Wu, P.-Y., Cheng, Y.-N., Uang, B.-J. "Enantioselective addition of organozinc reagents to carbonyl compounds catalyzed by a camphor derived chiral $\gamma$-amino thiol ligand", Tetrahedron, 72(21), pp. 2656-2665, 2016. https://doi.org/10.1016/j.tet.2015.07.038

[17] Rapi, Z., Démuth, B., Keglevich, G., Grün, A., Drahos, L., Sóti, P. L., Bakó, P. "Enantioselective Michael addition of malonates to aromatic nitroalkenes catalyzed by monosaccharide-based chiral crown ethers", Tetrahedron: Asymmetry, 25(2), pp. 141-147, 2014. https://doi.org/10.1016/j.tetasy.2013.12.007

[18] Kwiatkowski, J., Lu, Y. "Highly Enantioselective Michael Addition of 2-Fluoro-1,3-diketones to Nitroalkenes", European Journal of Organic Chemistry, 2015(2), pp. 320-324, 2015. https://doi.org/10.1002/ejoc.201403361

[19] Phillips, A. M. F. "Organocatalytic Asymmetric Nitro-Michael Reactions", Current Organic Synthesis, 13(5), pp. 687-725, 2016. https://doi.org/10.2174/1570179412666150914200843

[20] Kumar, S. A., Reddy, T. P., Madhavachary, R., Dhevalapally, B. R. "Rawal's catalyst as an effective stimulant for the highly asymmetric Michael addition of $\beta$-keto esters to functionally rich nitro-olefins", Organic \& Biomolecular Chemistry, 14(24), pp. 5494-5499, 2016. https://doi.org/10.1039/C5OB02178B

[21] Kaur, J., Islam, N., Kumar, A., Bhardwaj, V. K., Chimni, S. S. "Organocatalytic enantioselective synthesis of $\mathrm{C} 3$ functionalized indole derivatives", Tetrahedron, 72(49), pp. 8042-8049, 2016. https://doi.org/10.1016/j.tet.2016.10.037

[22] Bhorkade, S. B., Gavhane, K. B. "Multigram synthesis of an advanced nitroalkene intermediate: application in synthesis of octahydroindol-2-one derivative featuring diastereoselective Michael addition of diethylmalonate", Tetrahedron Letters, 57(24), pp. 2575-2578, 2016.

https://doi.org/10.1016/j.tetlet.2016.04.055

[23] Andrés, J. M., de La Cruz, N., Valle, M., Pedrosa, R. "Bottom-Up Synthesis of Supported Thioureas and Their Use in Enantioselective Solvent-Free Aza-Henry and Michael Additions", ChemPlusChem, 81(1), pp. 86-92, 2016. https://doi.org/10.1002/cplu.201500476

[24] Ogawa, T., Mouri, S., Yazaki, R., Kumagai, N., Shibasaki, M. "Intermediate as Catalyst: Catalytic Asymmetric Conjugate Addition of Nitroalkanes to $\alpha, \beta$-Unsaturated Thioamides", Organic Letters, 14(1), pp. 110-113, 2012. https://doi.org/10.1021/ol202898e

[25] Yang, H.-J., Xiang, F.-J., Chen, X.-F., Chen, F.-E. "Highly Enantioselective Thiolysis of Prochiral Cyclic Anhydrides Catalyzed by Amino Alcohol Bifunctional Organocatalysts and Its Application to the Synthesis of Pregabalin", European Journal of Organic Chemistry, 2013(21), pp. 4495-4498, 2013. https://doi.org/10.1002/ejoc.201300464

[26] Vakulya, B., Varga, S., Soós, T. "Epi-Cinchona Based Thiourea Organocatalyst Family as an Efficient Asymmetric Michael Addition Promoter: Enantioselective Conjugate Addition of Nitroalkanes to Chalcones and $\alpha, \beta$-Unsaturated N-Acylpyrroles", The Journal of Organic Chemistry, 73(9), pp. 3475-3480, 2008. https://doi.org/10.1021/jo702692a 
[27] Vaccaro, H. A., Zhao, Z., Clader, J. W., Song, L., Terracina, G., Zhang, L., Pissarnitski, D. A. "Solution-Phase Parallel Synthesis of Carbamates as $\gamma$-Secretase Inhibitors", Journal of Combinatorial Chemistry, 10(1), pp. 56-62, 2008. https://doi.org/10.1021/cc700100r

[28] Canale, V., Kurczab, R., Partyka, A., Satała, G., Lenda, T., Jastrzębska-Więsek, M., Wesołowska, A., Bojarski, A. J., Zajdel, P. "Towards new 5-HT 7 antagonists among arylsulfonamide derivatives of (aryloxy)ethyl-alkyl amines: Multiobjective based design, synthesis, and antidepressant and anxiolytic properties", European Journal of Medicinal Chemistry, 108, pp. 334-346, 2016. https://doi.org/10.1016/j.ejmech.2015.11.040

[29] Marchetti, P., Solomon, M. F. J., Szekely, G., Livingston, A. G. "Molecular Separation with Organic Solvent Nanofiltration: A Critical Review", Chemical Reviews, 114(21), pp. 1073510806, 2014 https://oi.org/10.1021/cr500006j

[30] Szekely, G., Jimenez-Solomon, M. F., Marchetti, P., Kim, J. F., Livingston, A. G. "Sustainability assessment of organic solvent nanofiltration: from fabrication to application", Green Chemistry, 16(10), pp. 4440-4473, 2014. https://doi.org/10.1039/C4GC00701H

[31] Razali, M., Kim, J. F., Attfield, M., Budd, P. M., Drioli, E., Lee, Y. M., Szekely, G. "Sustainable wastewater treatment and recycling in membrane manufacturing", Green Chemistry, 17(12), pp. 5196-5205, 2015.

https://doi.org/10.1039/C5GC01937K

[32] Janssen, M., Müller, C., Vogt, D. "Recent advances in the recycling of homogeneous catalysts using membrane separation", Green Chemistry, 13(9), pp. 2247-2257, 2011. https://doi.org/10.1039/C1GC15264E

[33] Wong, H., Pink, C. J., Ferreira, F. C., Livingston, A. G. "Recovery and reuse of ionic liquids and palladium catalyst for Suzuki reactions using organic solvent nanofiltration", Green Chemistry, 8(4), pp. 373-379, 2006.

https://doi.org/10.1039/B516778G

[34] Székely, G., Gil, M., Sellergren, B., Heggie, W., Ferreira, F. C. "Environmental and economic analysis for selection and engineering sustainable API degenotoxification processes", Green Chemistry, 15(1), pp. 210-225, 2013.

https://doi.org/10.1039/C2GC36239B

[35] Didaskalou, C., Buyuktiryaki, S., Kecili, R., Fonte, C. P., Szekely, G. "Valorisation of agricultural waste with an adsorption / nanofiltration hybrid process: from materials to sustainable process design", Green Chemistry, 19(13), pp. 3116-3125, 2017. https://doi.org/10.1039/C7GC00912G

[36] Székely, G., Schaepertoens, M., Gaffney, P. R. J., Livingston, A. G. "Beyond PEG2000: Synthesis and Functionalisation of Monodisperse PEGylated Homostars and Clickable Bivalent Polyethyleneglycols", Chemistry a European Journal, 20(32), pp. 10038-10051, 2014. https://doi.org/10.1002/chem.201402186

[37] Székely, G., Schaepertoens, M., Gaffney, P. R. J., Livingston, A. G. "Iterative synthesis of monodisperse PEG homostars and linear heterobifunctional PEG", Polymer Chemistry, 5(3), pp. 694-697, 2014. https://doi.org/10.1039/c3py01367g
[38] Kupai, J., Kisszékelyi, P., Rojik, E., Dargó, G., Hegedűs, L., Bezzegh, D., Maszler, P., Szabó, L., Németh, T., Balogh, G. T., Huszthy, P. "Synthesis and determination of $\mathrm{pKa}$ values of new enantiopure pyridino- and piperidino-18-crown-6 ethers", Arkivoc, 2016(4), pp. 130-151, 2016. https://doi.org/10.3998/ark.5550190.p009.592

[39] Nagy, S., Fehér, Z., Kisszékelyi, P., Huszthy, P., Kupai, J. "Cinchona derivatives as sustainable and recyclable homogeneous organocatalysts for aza-Markovnikov addition", New Journal of Chemistry, 42(11), pp. 8596-8602, 2018. https://doi.org/10.1039/C8NJ01277F

[40] Evans, D. A., Mito, S., Seidel, D. "Scope and Mechanism of Enantioselective Michael Additions of 1,3-Dicarbonyl Compounds to Nitroalkenes Catalyzed by Nickel(II)-Diamine Complexes", Journal of the American Chemical Society, 129(37), pp. 11583-11592, 2007. https://doi.org/10.1021/ja0735913

[41] Valtcheva, I. B., Kumbharkar, S. C., Kim, J. F., Bhole, Y., Livingston, A. G. "Beyond polyimide: Crosslinked polybenzimidazole membranes for organic solvent nanofiltration (OSN) in harsh environments", Journal of Membrane Science, 457, pp. 62-72, 2014. https://doi.org/10.1016/j.memsci.2013.12.069

[42] Székely, G., Valtcheva, I. B., Kim, J. F., Livingston, A. G. "Molecularly imprinted organic solvent nanofiltration membranes - Revealing molecular recognition and solute rejection behavior", Reactive and Functional Polymers, 86, pp. 215-224, 2015. https://doi.org/10.1016/j.reactfunctpolym.2014.03.008

[43] Kim, J. F., Szekely, G., Schaepertoens, M., Valtcheva, I. B., Jimenez-Solomon, M. F., Livingston, A. G. "In Situ Solvent Recovery by Organic Solvent Nanofiltration", ACS Sustainable Chemistry \& Engineering, 2(10), pp. 2371-2379, 2014. https://doi.org/10.1021/sc5004083

[44] Kim, J. F., Székely, G., Valtcheva, I. B., Livingston, A. G. "Increasing the sustainability of membrane processes through cascade approach and solvent recovery-pharmaceutical purification case study", Green Chemistry, 16(1), pp. 133-145, 2014. https://doi.org/10.1039/c3gc41402g

[45] Schaepertoens, M., Didaskalou, C., Kim, J. F., Livingston, A. G., Szekely, G. "Solvent recycle with imperfect membranes: A semi-continuous workaround for diafiltration", Journal of Membrane Science, 514, pp. 646-658, 2016. https://doi.org/10.1016/j.memsci.2016.04.056

[46] Razali, M., Didaskalou, C., Kim, J. F., Babaei, M., Drioli, E., Lee, Y. M., Szekely, G. "Exploring and Exploiting the Effect of Solvent Treatment in Membrane Separations", ACS Applied Materials \& Interfaces, 9(12), pp.11279-11289, 2017. https://doi.org/10.1021/acsami.7b01879

[47] Székely, G., Bandarra, J., Heggie, W., Sellergren, B., Ferreira, F. C. "A hybrid approach to reach stringent low genotoxic impurity contents in active pharmaceutical ingredients: Combining molecularly imprinted polymers and organic solvent nanofiltration for removal of 1,3-diisopropylurea", Separation and Purification Technology, 86, pp. 79-87, 2012.

https://doi.org/10.1016/j.seppur.2011.10.023 